International Journal of Pharmaceutics \& Pharmacology

EDW SER

Available Online: https://ijpp.edwiserinternational.com

\title{
Letter to Editor: Zoonotic Perspective of 2019 Novel Coronavirus Disease (COVID-19)
}

\author{
Arslan Habib ${ }^{*}$, Zeeshan Ashraf ${ }^{2}$, Umutumwa Eric Principe $^{3}$, Bilal Khalid ${ }^{4}$, Zahid Hussain ${ }^{5}$ and Malik \\ ShahZaib Khalid ${ }^{6}$
}

${ }^{1}$ Lab of Molecular Immunology, School of Life Sciences, Fudan University, Shanghai, China

${ }^{2}$ Department of Fisheries \& Aquaculture, University of Veterinary and Animals Sciences, Lahore, Pakistan

${ }^{3}$ School of Biotechnology, East China University of Science \& Technology, Shanghai, China

${ }^{4}$ Department of Zoology, University of the Punjab, Lahore, Pakistan

${ }^{5}$ Department of Zoology, Division of Science \& Technology, University of Education, Lahore, Pakistan

${ }^{6}$ Department of Zoology, University of the Punjab, Lahore, Pakistan

\section{Letter to Editor}

Recently Biscayart et al. stated that coronaviruses cause deleterious diseases in both humans and animals [1]. In the previous three decades China affected with different kinds of viral outbreaks in which include avian influenza disease in 1997, severe acute respiratory syndrome (SARS) in 2003 and severe fever with thrombocytopenia syndrome (SFTS) in 2010 [2]. The current outbreak of novel coronavirus disease (2019$\mathrm{nCoV}$ ) is much similar in case of symptoms with SARS$\mathrm{CoV}$ and Middle East respiratory syndrome $\mathrm{CoV}$ (MERS-CoV) [3]. The current pandemic of severe respiratory disease was first observed in Wuhan city of China which is more attractive in the central China. World Health Organization (WHO) office in China was first time observed infected individuals with unknown etiology of pneumonia in Wuhan city on 31 December 2019. The causative agent of this etiology was unknown at that time. After that the Chinese Centers for Disease Control and Prevention announced on 9th January that a novel strain of coronaviruses has been emerging out which is much similar to the previous outbreak of (SARS)-CoV monophyletic group may be the effective agents which are responsible for the current outbreak of Covid-19. Later on, it was confirmed that a novel strain of coronavirus responsible for the current outbreak is named as (SARS-CoV-2) [4]. Now it is very important to know about the reservoir of coronavirus, its dispensation and route of transmission. To control the further outbreaks of coronaviruses in future knowledge about the zoonotic aspects is very necessary. During the early pandemic of Covid-19 outbreak a study was designed in January 2020 in which 41 infected individuals were included with age near to 49 screened Covid-19 positive observed that half of patients confirmed with underlying diseases, which include hypertension and cardiac diseases $15 \%$ and diabetics $20 \%$. The symptoms associated with these patients include pyrexia $98 \%$, cough $76 \%$ and tiredness $44 \%$. The major obstacles of Covid019 patients include cardiac trauma $12 \%$, RNAaemia $15 \%$, respiratory syndrome $29 \%$ and some other secondary problems. All of the infected individuals which were $32 \%$ shifted to the Intensive Care Unit (ICU) and the mortality ratio was $15 \%$ [5]. Zoonotic diseases with emerging novel strains from infected animals to human caused serious diseases in the history. Animals are the possible source of diseases although it is thought that Covid-19 spread from the animal host, but it is not cleared which animal is the possible source of this outbreak. It was observed that bat coronavirus is associated $96 \%$ with the current pandemic of SARS-CoV-2 [2].

The basic aim of this study was to observe zoonotic outbreak of Covid-19 to humans. First time the coronaviruses were observed in the mid of 1960 which was known to infect other animals including mammals $\&$ birds and also humans. To understand zoonotic perspectives viral transmission can occur through different routes like fecal, oral, airborne and other contaminated objects. Almost seven different strains of coronaviruses that are infecting the humans have been identified until now. Infants and elders get infected with the familiar human coronaviruses which includes Betacoronavirus HCoVOC43 \& HCoV-HKU1 and Alphacoronavirus $\mathrm{HCoV}-229 \mathrm{E}$ which causes serious respiratory infections and common cold, while Alphacoronavirus HCoV-NL63 is the major causative agents of bronchiolitis in the infants [1]. However, new strains 
of coronaviruses have come out which caused serious infections in humans include severe acute respiratory syndrome coronavirus in 2002 (Betacoronavirus with subgenus Sarbecovirus) and Middle East respiratory coronavirus in 2012 (subgenus Merbecovirus). In 2019, a novel strain of coronavirus with unknown etiology of pneumonia patients was first time identified in Wuhan city of China and after that the pandemic named with coronavirus disease 2019 (Covid-19). The SARS-CoV2 is much associated with the SARS-CoV which genetically belongs to the Betacoronavirus with subgenus Sarbecovirus [1]. One more study was designed by $\mathrm{Li}$ and his coworkers with 425 highest numbers of infected patients in the age of 59 which recently visited Seafood Wholesale Market. The mean incubation period was 5.2 days and 56\% individuals were male. Different kinds of wild and domestic animals were sold unlawfully in the seafood market which is located at Wuhan city of China. Then it was observed that this zoonotic outbreak may be spreading from animal host to humans. However earlier transmission during the Covid-19 pandemic were from animal host which was reported by four infected patients from Seafood market of Wuhan but all the other infections that are globally transmitted are human to human. It was observed human to human transmission method was much active that spread to all the countries within less time. But the transmission mode from animals to human can be minimized in contrast to humans [2]. Recently human to human transmission has been increased in many directions and it can be transmitted through various ways like cough droplets or sneeze, public transport places, restaurants, medical departments, and other secondary public places. Different scientists illustrated that MERS-CoV is also a bat origin coronavirus strain from Africa or Saudi Arabia [6].

Table 1: Different coronavirus strains, their host and symptoms of infection.

\begin{tabular}{|c|l|c|c|l|}
\hline S. No. & Coronavirus strains & Primary host & Intermediate host & \multicolumn{1}{|c|}{ Symptom of infection } \\
\hline 1 & HCoV-229E & Bat & Camelids & Chest infection \\
\hline 2 & HCoV-HKU1 & Rat & Not defined & Acute pneumonia \\
\hline 3 & HCoV-OC43 & Bat & Not defined & $\begin{array}{l}\text { Mild upper respiratory } \\
\text { disease }\end{array}$ \\
\hline 4 & HCoV-NL63 & Bat & Camels & $\begin{array}{l}\text { Infections in respiratory } \\
\text { system } \\
\text { syndrome (37\% mortality) }\end{array}$ \\
\hline 5 & MERS-CoV & Bat racute respiratory \\
\hline 6 & SARS-CoV & Bat & Civets & $\begin{array}{l}\text { Harsh acute respiratory } \\
\text { syndrome (10\% mortality) }\end{array}$ \\
\hline 7 & SADS-CoV & Bat (Expected) & Not defined & $\begin{array}{l}\text { Acute diarrhea syndrome } \\
\text { Fever, Vomiting, shortness } \\
\text { of Breath, coughing, } \\
\text { pneumonia }\end{array}$ \\
\hline 8 & SARS-CoV-2 & & & \\
\hline
\end{tabular}

But it is still a question mark that how camel get infected with MERS-CoV from bats. For many years, camels had been known as a zoonotic reservoir for MERS-CoV [7]. Different studies suggested that infected bat is spreading the virus to the host which then act as an intermediate host and then virus transmitted to the humans from the intermediate host (Table 1) [11]. Bats have the high capacity of flying about more than 1000 $\mathrm{Km}$ which can transmit the virus to the different areas and at that time they adopted different new pathogens as a reservoir [8]. One of the major issues of SARSCoV-2 early transmission to other countries is the
Chinese New Year celebration resulted in the increased number of cases [9-11].

It is concluded that Covid-19 is a zoonotic disease. The burden of current pandemic emerging from bats is more significant as compared to the past coronaviruses like SARS-CoV and MERS-CoV. It is very important to understand the association of animals and humans in case of future zoonotic outbreaks worldwide. In the current medical conditions, the elders have the greater risk of infection as compared to the young ones. 


\section{References}

1. Biscayart C, Angeleri P, Lloveras S, et al. The next big threat to global health? 2019 novel coronavirus (2019-nCoV): What advice can we give to travellers? Interim recommendations January 2020, from the Latin-American society for Travel Medicine (SLAMVI). Travel Med Infect Dis 2020; 33: 101567.

2. Rodriguez-Morales AJ, Bonilla-Aldana DK, Balbin-Ramon GJ, et al. History is repeating itself: Probable zoonotic spillover as the cause of the 2019 novel Coronavirus Epidemic. Infez Med 2020; 28: 3-5.

3. Rodríguez-Morales AJ, Ramírez-Jaramillo V, Patiño-Barbosa AM, et al. Severe fever with thrombocytopenia syndrome-A bibliometric analysis of an emerging priority disease. Travel Med Infect Dis 2018; 23: 97.

4. Bhattacharya M, Sharma AR, Patra P, et al. Development of epitope-based peptide vaccine against novel coronavirus 2019 (SARS-COV-2): Immunoinformatics approach. J Med Virol 2020; 92: 618-631.
5. Bastola A, Sah R, Rodriguez-Morales AJ, et al. The first 2019 novel coronavirus case in Nepal. Lancet Infect Dis 2020; 20: 279-280.

6. Memish ZA, Mishra N, Olival KJ, et al. Middle East respiratory syndrome coronavirus in bats, Saudi Arabia. Emerg Infect Dis 2013; 19: 1819.

7. Banerjee A, Kulcsar K, Misra V, Frieman M, Mossman K. Bats and coronaviruses. Viruses 2019; 11: 41 .

8. McGuire LP, Fenton MB, Guglielmo CG. Phenotypic flexibility in migrating bats: seasonal variation in body composition, organ sizes and fatty acid profiles. J Exp Biol 2013; 216: 800-808.

9. Ahmad T, Khan M, Haroon THM, et al. COVID19: Zoonotic aspects. Travel Med Infect Dis 2020; 101607.

10. Jahangir MA, Muheem A, Rizvi MF. Coronavirus (COVID-19): history, current knowledge and pipeline medications. Int J Pharm Pharmacol 2020; 4: 140.

11. Chakraborty C, Sharma AR, Bhattacharya M, et al. The 2019 novel coronavirus disease (COVID-19) pandemic: A zoonotic prospective. Asian Pac J Trop Med. 2020; 13: 242.
*Corresponding author: Arslan Habib, Lab of Molecular Immunology, School of Life Sciences, Fudan University, Shanghai, China

\section{Article Info}

Received 15 December 2020

Revised 29 December 2020

Available Online 02 January 2021

Copyright: (C2021 Habib A, et al. This article is distributed under the terms of the Creative Commons Attribution 4.0 International License (http://creativecommons.org/licenses/by/4.0/), which permits unrestricted use, distribution, and reproduction in any medium, provided you give appropriate credit to the original author(s) and the source, provide a link to the Creative Commons license, and indicate if changes were made. 